\title{
Three-dimensional transvaginal ultrasound: clinical implementation in assessing uterine cavity
}

\author{
Abdelaziz E. Tammam*, Mostafa M. Khodry, Shymaa M. A. Elnagar, Ahmed H. Abdella, \\ Sayed A. M. Taha
}

Department of Obstetrics \& Gynaecology, Faculty of Medicine, South Valley University, Qena, Egypt

Received: 06 September 2015

Accepted: 20 September 2015

\section{*Correspondence:}

Dr. Abdelaziz E. Tammam,

E-mail: tamamkena@yahoo.com

Copyright: (C) the author(s), publisher and licensee Medip Academy. This is an open-access article distributed under the terms of the Creative Commons Attribution Non-Commercial License, which permits unrestricted non-commercial use, distribution, and reproduction in any medium, provided the original work is properly cited.

\begin{abstract}
Background: Three-dimensional transvaginal ultrasonography (3D TVS) represents a new technique of imaging and provides a unique diagnostic tool for non-invasive examination of the uterine morphology and diagnosis of congenital uterine anomalies. In this study the clinical value of 3D TVS in diagnosis of uterine cavity abnormalities were evaluated.

Methods: A prospective of diagnostic accuracy study included 226 patients with various clinical presentations; infertility, recurrent pregnancy loss, menstrual disorders and post-menopausal bleeding with suspected uterine cavity lesions or abnormality on two-dimensional (2D) TVS or hysterosalpingography (HSG). After taking consent, all patients were subjected to history taking, clinical examination, 3D TVS evaluation, magnetic resonance imaging (MRI) and finally endoscopic examination.

Results: The 3D has $98 \%$ accuracy in infertile women in comparison to $87 \%$ for MRI. While with recurrent pregnancy loss, Concordance was $96 \%$ correct for 3D and $78 \%$ for MRI. The women with abnormal uterine bleeding, the accuracy of 3D was $100 \%$, while with MRI was $74 \%$. The sensitivity of 3D TVS was $97.8 \%$ and $100 \%$ specificity, positive and negative predictive value. While the sensitivity, specificity, positive and negative predictive values for MRI were $89.3 \%, 64 \%, 70.4 \%$ and $86.3 \%$ respectively.

Conclusions: 3D TVS appears to be extremely accurate, less expensive and a rapid examination for the diagnosis and classification of uterine anomalies, more than MRI. Thus it may become the only mandatory step in the assessment of the uterine cavity.
\end{abstract}

Keywords: 3D transvaginal ultrasound, Clinical implementation, Uterine cavity

\section{INTRODUCTION}

Three-dimensional transvaginal ultrasound (3D TVS) represents a new technique of imaging. It has the ability to register all three imaging planes simultaneously as well as to visualize surfaces three dimensionally. Threedimensional TVS enables visualization of the uterus in the coronal plane, which is rarely seen on conventional scans It thus provides a unique diagnostic tool for noninvasive studies of the uterine morphology and diagnosis of congenital uterine anomalies. ${ }^{1-3}$ The coronal plane of the uterus is used to visualize both horns of the endometrium and the cervix at the same time. ${ }^{4}$ Also, improves the visualization of possible interactions between structures such as uterine fibroid sand polyps. ${ }^{5}$ The frontal plan of the uterus also offers marked improvements for studying uterine malformations, especially in cases of infertility. ${ }^{6}$ 3D TVS is helpful in delineation of intracavitary adhesions and determination of their location that assists in surgical planning. ${ }^{7}$ In addition, by $3 \mathrm{D}$ ultrasound more precise anatomical sections for exploring the endometrial cavity; the 
relations of myomata and their possible encroachment on the cavity, the diagnosis of endometrial polypi and the measurement of endometrial volume rather than thickness in cases of abnormal uterine bleeding. ${ }^{8}$ 3D TVS represents a useful alternative, for lower cost $\&$ better tolerance by the patient. It provides images of a very similar quality of those of MRI. ${ }^{9}$ A combined hysteroscopic and laparoscopic evaluation of uterine morphology and contour has been the most widely used method, but remains an invasive procedure that should no more be used as gold-standard. More recently, 3D TVS has been reported to have a very high accuracy rate in diagnosing congenital anomalies. ${ }^{10}$ It is a non-invasive and reproductive procedure that assesses both the internal and external contour of the uterus by displaying the coronal plane of the uterus. ${ }^{11}$ It is now more and more recommended as the first diagnostic step in the assessment of the uterine cavity. ${ }^{4}$ Saline infusion of the uterus has been used to improve the internal delineation of the uterine contour. ${ }^{12}$ Pelvic magnetic resonance imaging (MRI) has also been advocated for the noninvasive diagnosis of uterine anomalies ${ }^{13}$. This study was done to evaluate the clinical value of $3 \mathrm{D}$ TVS in diagnosis of uterine disorders in patients with different gynaecological complaint.

\section{METHODS}

A prospective study of diagnostic accuracy was conducted at the Obstetrics and Gynecology Department of Qena University Hospital at the period between January 2012 and April 2014. The study included 176 patients in the age group between 18-73 years. Various clinical presentations were encountered in the study group including; infertility, recurrent pregnancy loss (RPL), menstrual disorders and post-menopausal bleeding. All patients who were suspected to have a uterine cavity lesion or abnormality on two-dimensional (2D) TVS or hysterosalpingography (HSG) were encountered. After taking consent, all patients were subjected to history taking, clinical examination, 3D TVS evaluation, MRI and finally operative endoscopy.

\section{Technique}

Each patient was examined by using two dimensional Bmode transvaginal ultrasound $7.5 \mathrm{MHz}$ mechanical probe. A systematic examination include; the assessment of the uterine position, size, and morphological characteristics.

The ultrasound system equipped with an endovaginal volume probe (SonoAce X8, MNT17 X8) with a frequency of 5 to $9 \mathrm{MHz}$, was used for all 3D TVS. After visualizing the uterus in the $2 \mathrm{D}$ TVS longitudinal plane, a volume was acquired by the automatic mechanical sweep of the electronic transducer. To enhance the visualization of the malformation, sono-hysterography (3D SHG) was performed for each patient. The 3D sono-hysterography was carried out by the intrauterine injection of an isotonic saline solution $20 \mathrm{~mL}$, and a second volume will be acquired. The volumes were then being displayed in the multi-planar view. This rendering modality allows analysis of the volumes in 3 orthogonal planes and obtains the coronal view showing the external and the fundal contours of the uterus. The uterine structure was studied on the basis of the coronal view information and with the interstitial portions of fallopian tubes used as reference points. The study was approved by the ethical committee of the Qena university hospital and written consent was taken from all participants.

\section{Statistics}

Results were analysed using sensitivity (SE), specificity (SP), positive predictive value (PPV), negative predictive value (NPV) and positive and negative likelihood ratios (PLR, NLR). All statistical calculations were done using Microsoft Excel ${ }^{\circledR}$ and SPSS $®$ (Statistical Package for the Social Science) (Version 16.0 SPSS Inc. (Chicago, IL).

\section{RESULTS}

Table 1: Accuracy of 3D in diagnosis of uterine abnormalities in patients with infertility.

\begin{tabular}{|lccc|}
\hline Findings & 3D SHG & MRI & Endoscopy \\
\hline $\begin{array}{l}\text { Bicornuate } \\
\text { uterus }\end{array}$ & 11 & 16 & 11 \\
\hline $\begin{array}{l}\text { False } \\
\text { positive }\end{array}$ & - & 5 & - \\
\hline $\begin{array}{l}\text { Septate } \\
\text { uterus }\end{array}$ & 16 & 14 & 16 \\
\hline $\begin{array}{l}\text { False } \\
\text { positive }\end{array}$ & - & 0 & - \\
\hline $\begin{array}{l}\text { Submucous } \\
\text { fibroid }\end{array}$ & 19 & 26 & 19 \\
\hline $\begin{array}{l}\text { False } \\
\text { positive }\end{array}$ & - & 7 & - \\
\hline $\begin{array}{l}\text { Fibroid } \\
\text { polyp }\end{array}$ & 31 & 25 & 31 \\
\hline $\begin{array}{l}\text { False } \\
\text { positive }\end{array}$ & - & 0 & - \\
\hline $\begin{array}{l}\text { Intrauterine } \\
\text { adhesions }\end{array}$ & 8 & 6 & 10 \\
\hline $\begin{array}{l}\text { False } \\
\text { positive }\end{array}$ & 0 & 0 & $87 / 87$ \\
\hline $\begin{array}{l}\text { Concordance } \\
\text { with } \\
\text { endoscopy }\end{array}$ & $85 / 87$ & $76 / 87$ & $(100 \%)$ \\
\hline
\end{tabular}

As regard to the gynaecological complaints the clinical presentations of the patients need skills for evaluation so, familial contact with the easy non-invasive techniques with less cost is helpful to catch the diagnosis. 176 patients were diagnosed by endoscopy to have uterine cavity abnormalities from 226 patients those were suspected to have uterine abnormalities. In our study the most frequent clinical gynaecological presentation was the infertility $(50 \%)$ followed by the abnormal uterine 
bleeding (29\%), while those with recurrent pregnancy loss were $21 \%$.

Table 2: Accuracy of 3D in diagnosis of uterine abnormalities in patients with recurrent pregnancy loss.

\begin{tabular}{|lccc|}
\hline Findings & 3D SHG & MRI & Endoscopy \\
\hline $\begin{array}{l}\text { Bicornuate } \\
\text { uterus }\end{array}$ & 4 & 9 & 4 \\
\hline $\begin{array}{l}\text { False } \\
\text { positive }\end{array}$ & - & 5 & - \\
\hline $\begin{array}{l}\text { Septate } \\
\text { uterus }\end{array}$ & 18 & 14 & 18 \\
\hline $\begin{array}{l}\text { False } \\
\text { positive }\end{array}$ & - & 0 & - \\
\hline $\begin{array}{l}\text { Submucous } \\
\text { fibroid }\end{array}$ & 11 & 17 & 11 \\
\hline $\begin{array}{l}\text { False } \\
\text { positive }\end{array}$ & - & 6 & - \\
\hline $\begin{array}{l}\text { Fibroid } \\
\text { polyp }\end{array}$ & 9 & 6 & 9 \\
\hline $\begin{array}{l}\text { False } \\
\text { positive }\end{array}$ & - & 0 & - \\
\hline $\begin{array}{l}\text { Intrauterine } \\
\text { adhesions }\end{array}$ & 6 & 4 & - \\
\hline $\begin{array}{l}\text { False } \\
\text { positive }\end{array}$ & - & 0 & $\begin{array}{c}50 / 50 \\
(100 \%)\end{array}$ \\
\hline $\begin{array}{l}\text { Concordance } \\
\text { with } \\
\text { endoscopy }\end{array}$ & $48 / 50$ & $\begin{array}{l}39 / 50 \\
(78 \%)\end{array}$ & \\
\hline
\end{tabular}

The 3D TVS has $100 \%$ accuracy in diagnosis of the congenital anomalies, submucous fibroid and fibroid polyp in comparison to the laparoscopy and hysteroscopy while it has a false negative 2 cases in diagnosis of the intrauterine adhesions in infertile patients. The magnetic resonance imaging concordance with endoscopy was $87 \%$ (Table 1).

Table 2 shows the concordance between 3D TVS and endoscopy was verified in 42 cases with congenital anomalies, submucous fibroid and fibroid polyp, the diagnosis was $100 \%$ correct. 6 cases with intrauterine adhesions were diagnosed by 3D TVS with correct diagnosis $6 / 8$ patients (75\%) with 2 false-negative cases. Magnetic resonance imaging was obtained in all 50 cases and the correct diagnosis was $39 / 50$ patients (78\%).

The present study included 39 patients complaining of abnormal uterine bleeding. The most common bleeding pattern was menorrhagia $(40 \%)$ followed by menometrorrhagia $(22.8 \%)$ then metrorrhagia (34.2\%) then polymenorrhoea (2.8\%). 3D TVS were detecting 21 myomas and 18 polyps with correct diagnosis $100 \%$. Magnetic resonance imaging detected 26 myomas and 13 polyps with accuracy $74 \%$ (Table 3 ).
The accuracy of the 3D TVS in the diagnosis of uterine disorders in patients with different gynaecological complaint nearby similar to the endoscopic diagnosis (Figure 1). The sensitivity of 3D TVS was $97.8 \%$ and $100 \%$ specificity, positive and negative predictive value. The sensitivity, specificity positive and negative predictive values for MRI was $89.3 \%, 64 \%, 70.4 \%$ and $86.3 \%$ respectively.

Table 3: Accuracy of 3D in Diagnosis of uterine lesions in abnormal uterine bleeding.

\begin{tabular}{|lccc|}
\hline Findings & 3D SHG & MRI & Endoscopy \\
\hline $\begin{array}{l}\text { Submucous } \\
\text { fibroid }\end{array}$ & 21 & 26 & 21 \\
\hline $\begin{array}{l}\text { False } \\
\text { positive }\end{array}$ & 0 & 5 & - \\
\hline $\begin{array}{l}\text { Endometrial } \\
\text { polyp }\end{array}$ & 18 & 13 & 18 \\
\hline $\begin{array}{l}\text { False } \\
\text { positive }\end{array}$ & 0 & 0 & - \\
\hline $\begin{array}{l}\text { Concordance } \\
\text { with } \\
\text { endoscopy }\end{array}$ & $\begin{array}{c}39 / 39 \\
(100 \%)\end{array}$ & $\begin{array}{c}29 / 39 \\
(74 \%)\end{array}$ & $\begin{array}{c}39 / 39 \\
(100 \%)\end{array}$ \\
\hline
\end{tabular}

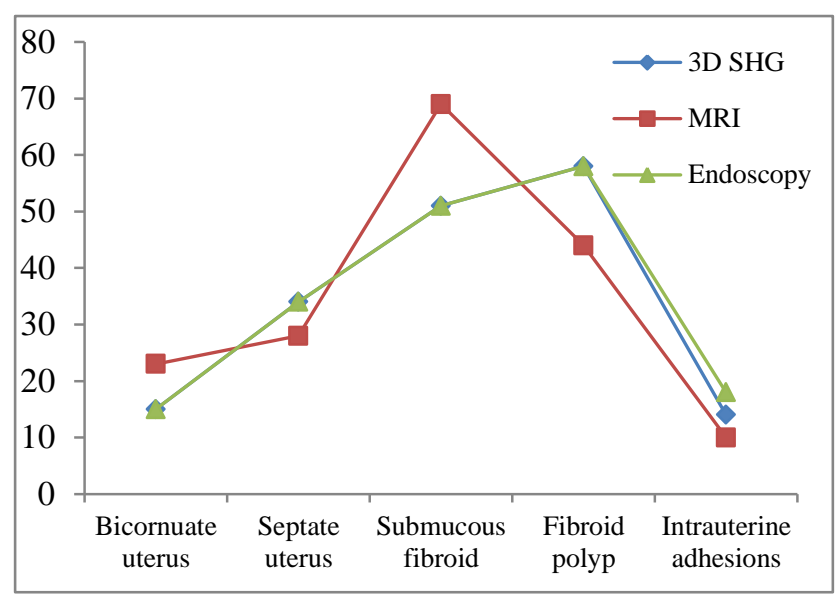

Figure 1: Concordance between 3D TVS and MRI with endoscopy in different gynecological complaints.

\section{DISCUSSION}

The 3D TVS considered an easy and non-invasive office procedure. Furthermore, it visualizes the frontal (coronal) plane of the uterus. ${ }^{14}$ Congenital uterine anomalies are associated with an increased risk of repeated first and second trimester miscarriage and preterm delivery. ${ }^{15}$ The purpose of our study was to compare transvaginal 3D sonohysterography and MRI with endoscopy as a standard tool in the diagnosis of uterine abnormalities in patients with different clinical presentations. 176 of patients from 226 patients evaluated were included in our study $50 \%$ of them were infertile.

Our results were compared to the gold standard hysteroscopy and laparoscopy and this explains why 
intramural fibroids were not included in the overall accuracy of our diagnostic techniques. This elicits the importance of TV ultrasound as the primary diagnostic technique for uterine abnormalities such as myomas and adenomyosis. The added benefit of saline injection sonohysterography in the diagnosis of uterine abnormalities has been well documented in our results showing a much higher accuracy of 3D sonohysterography as compared to MRI; $98 \%$ versus $74 \%$ in patients with infertility, in RPL accuracy was $96 \%$ versus $76 \%$ while in those with uterine bleeding $100 \%$ for $3 \mathrm{D}$ versus $74 \%$ for MRI.

The favourable results suggesting that three dimensional sonography offered $100 \%$ specificity for the exclusion of uterine anomalies and was able to differentiate between the different anomalies. ${ }^{6}$ In our study, 3D TVS showed high SE $(97.8 \%)$ and SP $(100 \%)$ for the detection of uterine cavity anomalies. Clinically, many women presenting with fertility problems are found to have Asherman's syndrome during routine infertility work-up. The data obtained from three dimensional ultrasound correlates more closely with the character and extent of Asherman's disease, it could be a helpful tool in predicting fertility outcome postoperatively. ${ }^{16}$

Our data confirm that 3D TVS were extremely accurate for the diagnosis and classification of septate and bicornuate uterus. Concordance between ultrasonography and hysteroscopy/laparoscopy concerning the type of anomaly was verified in all the cases. As the most commonly used methods for investigating suspected congenital anomalies, neither hysterosalpingography nor hysteroscopy enable the accurate evaluation of the uterine fundus. In comparison with hysteroscopy, the accuracy of 3D ultrasonography in the screening of congenital anomalies was $100 \% .^{11,17}$

MRI offers a non-invasive approach of assessing the internal and the external contour of the uterus with a high degree of concordance between 3D ultrasonography and MRI in the diagnosis of uterine malformation. ${ }^{18}$ In our study, only $74 \%$ accuracy in patients with infertility, while in those with RPL diagnoses were $76 \%$ correct and those complaining from abnormal uterine bleeding, the accuracy was $74 \%$ with MRI. The diagnosis of synaechae was the main factor in decreasing the accuracy values for 3D TVS and MRI exclusion of the synaechae the accuracy of the 3D TVS was $100 \%$ for all uterine anomalies with different complaint.

The prevalence of septa in patients who have had recurrent pregnancy loss is well known, with reported spontaneous abortion rates from $26 \%$ to $94 \% .{ }^{19}$ MRI has emerged as an excellent technique for evaluation of mullerian duct anomalies (MDAs). ${ }^{13,20}$ The efficacy of MRI for MDA evaluation with an overall accuracy of $100 \%$, 3D ultrasound has the advantage over MRI as it is less expensive and better tolerated by patients. ${ }^{18} 3 \mathrm{D}$ ultrasound aided us to make measurements of the septum such as length and thickness. The volume of the cavity can be calculated as well as the study of septal vascularization, which can affect fertility prognosis, thus helping the choice of treatment. ${ }^{4}$ As 3D TVS becomes more common and the physicians more skilled in evaluating uterine volumes, 3D TVS will be the reference standard for the diagnosis of MDAs. ${ }^{21}$ The 3D TVS appears to be extremely more accurate than MRI for the diagnosis and differentiating septate and bicornuate uterus. $^{22}$

The main pathology findings in patients with abnormal uterine bleeding were endometrial polyps $(45.9 \%)$ and submucous myomas $(28 \%){ }^{2}$ these findings were comparable with our findings which detected 21 myomas and 18 polyps with correct diagnosis $100 \%$ by 3DTVS, while MRI detected 26 myomas and 13 polyps with accuracy $74 \%$. Thus, computerized reconstruction of $3 \mathrm{D}$ hysterosonography may in the future support the use of 3D ultrasound in characterization of intrauterine lesions.

Hysteroscopy is an important method for the diagnosis of intrauterine pathology in several gynaecologic complaints. However, diagnostic hysteroscopy is an invasive and costly procedure, which may be associated with risks. $^{23} 3 \mathrm{D}$ TVS has been commercially available and this technique allows detailed evaluation of pelvic organs. Also, the sensitivity of 3D TVS was $97.8 \%$ and specificity, positive and negative predictive value was $100 \%$, which were higher than the values for MRI $(89.3 \%, 64 \%, 70.4 \%$ and $86.3 \%$ respectively).

\section{CONCLUSIONS}

3D TVS appears to be extremely accurate, less expensive and a rapid examination for the diagnosis and classification of uterine anomalies, more than MRI. So, enables the clinician to assess uterine morphologic characteristics completely, thus alleviating the need for invasive and costs tests. Thus 3D TVS may become the only mandatory step in the assessment of the uterine cavity in patients with a different gynaecological complaint.

\section{Funding: No funding sources Conflict of interest: None declared \\ Ethical approval: The study was approved by the Institutional Ethics Committee}

\section{REFERENCES}

1. Moeglin D, Benoit B, De Ziegler D. Advantages of studying the frontal plane of the uterine cavity in $3 \mathrm{D}$ ultrasound. Contracept Fertil Sex. 1999;27:710-20.

2. Ayoubi JM, Fanchin R, Ferretti G, Pons JC, Bricault I. Three-dimensional ultrasonographic reconstruction of the uterine cavity: toward virtual hysteroscopy? Eur Radiol. 2002;12:2030-3.

3. Kupesic S, Kurjak A, Skenderovic S, Bjelos D. Screening for uterine abnormalities by three- 
dimensional ultrasound improves perinatal outcome. Perinat Med. 2002;30:9-17.

4. Salim R, Woelfer B, Backos M, Regan L, Jurkovic D. Reproducibility of three-dimensional ultrasound diagnosis of congenital uterine anomalies. Ultrasound Obstet Gynecol. 2003;21:578-82.

5. La Torre R, De Felice C, De Angelis C, Coacci F, Mastrone M, Cosmi EV. Transvaginal sonographic evaluation of endometrial polyps: a comparison with two dimensional and three dimensional contrast sonography. Clin Exp Obstet Gynecol. 1999;26:1713.

6. Raga F, Bonilla-Musoles F, Blanes J, Osborne N.Congenital Mullerian Anomalies: Diagnostic accuracy of three-dimensional ultrasound. Fertile Steril. 1996;65:523-8.

7. Balen FG, Allen CM, Gardener JE, Siddle NC, Lees WR. Three-Dimensional reconstruction of ultrasound images of the uterine cavity. $\mathrm{Br} \mathrm{J}$ Radiol 1993;66:588-91.

8. Fenester A, Downey DB. Three dimensional ultrasound imaging : a review. IEEE Eng Med Biol 1996; 15:41- 51.

9. Deutch TD, Abuhamad AZ. The role of 3dimensional ultrasonography and magnetic resonance imaging in the diagnosis of Mullerian duct anomalies: a review of the literature. J Ultrasound Med 2008;27:413-23.

10. Ghada K. Gouhar and Soha Siam. Uterine septum structure and reproductive performance: Role of 3D TVU and MRI. The Egyptian Journal of radiology and nuclear Medicine. 2013;44:357-65.

11. Ghi T, Casadio P, Kuleva M, et al. Accuracy of three-dimensional ultrasound in diagnosis and classification of congenital uterine anomalies. Fertil Steril. 2009;92:808-13.

12. Alborzi S, Dehbashi S, Parsanezhad M. Differential diagnosis of septate and bicornuate uterus by sonohysterography eliminates the need for laparoscopy. Fertil Steril. 2002;78:176-8.

13. Saleem SN. MR Imaging diagnosis of uterovaginal anomalies: current state of the art. Radiographics. 2003;23:e13.

14. Kiyokawa K, Masuda H, Fuyuki T, Koseki M, Uchida $\mathrm{N}$ and Fukuda $\mathrm{T}$. Three dimensional hysterosalpingocontrast-sonography "3D-Hycosy" as an outpatient procedure to assess infertile women: a pilot study. Ultrasound Obstet Gynecol 2000;16:64854.

15. Kupesic. Clinical implications of sonographic detection of uterine anomalies for reproductive outcome. Ultrasound Obstet Gynecol. 2001;18(4):387-400.

16. Kyei-Mensah A, Zaidi J, Pittrop R, Shaker AA, Campbell S, Tan SL. Threedimensional ultrasound: accuracy of follicular volume measurements. Fertil. Steril. 1996;65:371-6.

17. Makris N, Kalmantis K, Skartados N, Papadimitriou A, Mantzaris G, Antsaklis A. Three-dimensional hysterosonography versus hysteroscopy for the detection of intracavitary uterine abnormalities. Int $\mathbf{J}$ Gynaecol Obstet. 2007;97:6-9.

18. Bermejo C, Martı'nez Ten P, Cantarero R, Diaz D, Pe'rez Pedregosa J, Barro' $\mathrm{n}$ E, et al. Threedimensional ultrasound in the diagnosis of $\mathrm{mu}$ * llerian duct anomalies and concordance with magnetic resonance imaging. Ultrasound Obstet Gynecol. 2010;35:593-601.

19. Propst AM, Hill JA. Anatomic factors associated with recurrent pregnancy loss. Semin Reprod Med. 2000; 18:341-50.

20. Troiano RN. Magnetic resonance imaging of mullerian duct anomalies of the uterus. Top Magn Reson Imaging. 2003;14:269-79.

21. Todd D, Deutch MD, Alfred Z, Abuhamad MD. The role of 3-dimensional ultrasonography and magnetic resonance imaging in the diagnosis of mu“ llerian duct anomalies. J Ultrasound Med. 2008;27:413-23.

22. Faivre E, Fernandez H, Deffieux X, Gervaise A, Frydman R, Levaillant JM. Accuracy of threedimensional ultrasonography in differential diagnosis of septate and bicornuate uterus compared with office hysteroscopy and pelvic magnetic resonance imaging. J Minim Invasive Gynecol. 2012;19(1):101-6.

23. Jurkovic D. Three-dimensional ultrasound in gynecology: a critical evaluation. Ultrasound Obstet Gynecol. 2002;19:109-117.

Cite this article as: Tammam AE, Khodry MM, Elnagar SMA, Abdella AH, Taha SAM. Threedimensional transvaginal ultrasound: clinical implementation in assessing uterine cavity. Int $\mathbf{J}$ Reprod Contracept Obstet Gynecol 2015;4:1272-6. 